\title{
Measuring the financial effects of mitigating commodity price volatility in supply chains
}

\author{
Barbara Gaudenzi \\ Department of Business Administration, University of Verona, Verona, Italy \\ George A. Zsidisin \\ Department of Supply Chain and Analytics, College of Business Administration, \\ University of Missouri - St. Louis, Saint Louis, Missouri, USA, and \\ Roberta Pellegrino \\ Department of Mechanics Mathematics and Management - Polytechnic University of Bari, Bari, Italy
}

\begin{abstract}
Purpose - Firms can choose from an array of approaches for reducing the detrimental financial effects caused by unfavorable fluctuations in commodity prices. The purpose of this paper is to provide guidance for effectively estimating the financial effects of mitigating commodity price risk volatility (CPV) in supply chain management decisions.

Design/methodology/approach - This paper adopts two prominent and complementary methodologies, namely, total cost of ownership (TCO and real options valuation (ROV), to illustrate how commodity price risk mitigation strategies can be analyzed with respect to their effect on costs and performance. The paper provides insights through a case study to demonstrate the application of these methods together and establish the benefits and challenges associated with their implementation.

Findings - The paper illustrates advantages and disadvantages of TCO and ROV and how these approaches can be adopted together to contribute to effective purchasing decisions. Supply chain flexibility is a key capability but requires investments. Holistically measuring the financial effects of flexibility investments is imperative for gaining executive management support in mitigating commodity price volatility.

Research limitations/implications - This study can provide supply chain professionals with useful guidance for measuring the costs and benefits related to developing strategies for mitigating commodity price volatility. TCO provides a focus on the costs associated with the commodity purchasing process, and ROV enables the aggregation of all the costs and benefits associated with the use of the strategy and synthesizes them into the net value estimate.

Originality/value - The paper provides a comparison of different but complementary approaches, specifically TCO and ROV, for analyzing the effectiveness of CPV risk mitigation decisions. In addition, these two methods allow supply chain professionals to evaluate and control the financial effects of CPV risk, particularly the impact of mitigation on firm's cash flows.
\end{abstract}

Keywords Purchasing, Supply chain risk, Commodity price volatility, Risk mitigation, Total cost of ownership, Real options valuation, Risk management, Supply risk, Commodities

Paper type Research paper

\section{Introduction}

Most organizations purchase commodities in some form as part of its firm's operations. Commodities, such as metals (e.g. steel, aluminum, copper, silver, gold), energy (e.g. natural gas, oil) and agricultural products (e.g. wheat, corn, soybeans) can be acquired directly as raw material inputs to a firm's products, indirectly as components of purchased items from a firm's suppliers, and/or as part of a firm's operations and overhead expenses (Zsidisin et al., 2013). Commodities are a significant input affecting many industries: steel for automotive or electronics companies, lead for battery manufacturing, agricultural commodities for food companies and jet fuel in the airline industry are just a few examples. When an extensive

The current issue and full text archive of this journal is available on Emerald Insight at: https://www.emerald.com/insight/1359-8546.htm

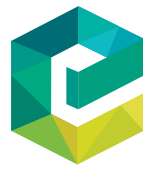

Supply Chain Management: An International Journal 26/1 (2021) 17-31

Emerald Publishing Limited [ISSN 1359-8546] [DOI 10.1108/SCM-02-2020-0047] portion of the firm's overall purchases consists of price-volatile commodities, a key concern is commodity prices changing sharply, putting the company's economic viability at risk (Fischl et al., 2014; Bandaly et al., 2014). If not effectively managed, commodity price volatility (CPV) may severely undermine the ability to meet customer requirements, creating challenges for product pricing decisions, budget planning and

(C) Barbara Gaudenzi, George A. Zsidisin and Roberta Pellegrino. Published by Emerald Publishing Limited. This article is published under the Creative Commons Attribution (CC BY 4.0) licence. Anyone may reproduce, distribute, translate and create derivative works of this article (for both commercial and non-commercial purposes), subject to full attribution to the original publication and authors. The full terms of this licence may be seen at http://creativecommons.org/licences/by/4.0/legalcode

We would like to thank Dr Florian Schupp for helping motive this study and his insights, an anonymous contributor for providing the context and data used in this research, and the reviewers for improving the manuscript.

Received 1 February 2020

Revised 16 June 2020

22 June 2020

Accepted 27 June 2020 
net cash flow management (Kaufmann et al., 2017; Finley and Pettit, 2011; Matook et al., 2009).

From a supply chain risk management (SCRM) perspective, CPV has been considered as a subcategory of supply chain risk (Fischl et al., 2014). During the past years, different approaches have been discussed for mitigating CPV. In particular, Bandaly et al. (2014) highlighted the key role of cross-functional collaboration between operations and finance to minimize the expected total opportunity cost related to upstream commodity price fluctuations and downstream demand variability. Several risk mitigation strategies have been identified from the financial perspective, namely, financial hedging (Sun et al., 2017; Caniato et al., 2016), and from the SCRM perspective, specifically sourcing approaches (forward buying, switching supplier, substituting commodities, vertical integration) (Manikas and Kroes, 2016) and contracting strategies (escalator clauses, staggering contracts, passing price increase to customers) (Gaudenzi et al., 2018; Zsidisin et al., 2013; Wakolbinger and Cruz, 2011). All of these strategies are characterized by different thresholds between costs and benefits, which need to be carefully evaluated by supply management professionals before implementing measures to mitigate this form of risk. Hence, companies should calculate how risk mitigation strategies reduce the negative effects of CPV. Despite this practical need, the existing SCRM literature on CPV and its mitigation has mainly focused on analyzing how firms perceive CPV and how CPV affects profitability along its supply chain (Zsidisin and Hartley, 2012). Others have analyzed the range of possible mitigation strategies available to supply chain managers for mitigating CPV (Liu and Wang, 2019; Zsidisin et al., 2015), which are the main factors influencing the choice of CPV mitigation strategies (Gaudenzi et al., 2018) and how the concept of flexibility may be leveraged for building the mitigation capability of specific SCRM strategies in dealing with CPV (Pellegrino et al., 2019; Costantino et al., 2016).

There is a lack of structured tools benchmarking commodity price risk mitigation strategies for understanding which approaches are more effective and efficient in mitigating commodity price risk and the conditions under which some strategies perform better than others. In addition, both practitioners and academics highlight the need to further investigate how to mitigate emerging risks, such as CPV, affecting supply chains (Kumar and Park, 2019; Manikas and Kroes, 2016; Bandaly et al., 2014). This paper aims to fill the abovementioned gaps, from both practical and theoretical perspectives, and develops an approach for better measuring the financial and operational performance effects from implementing risk mitigation strategies. The measures are based upon two prominent approaches, namely, total cost of ownership (TCO) and real options valuation (ROV). The rationale for using these two approaches is twofold. First, they both assess the financial effects of mitigating CPV, namely, the impact that strategy adoption has on firm cash flows (Carmichael, 2016). The different risk mitigation strategies (financial hedging, sourcing approaches and contracting strategies) have different features which often are non-comparable. TCO can potentially support decision-makers through the monetary quantification and aggregation of these features. Specifically, features that are not naturally expressed as a financial unit of measure are "translated" into financial numbers (Morssinkhof et al., 2011). Further, several CPV mitigation strategies build their mitigation capability on creating flexibility, whose value may be well captured in financial terms by ROV approach rather than pure discounted cash flow (DCF)-based tools (Pellegrino et al., 2019; Carmichael, 2016; Carmichael, 2015). The second reason for combining these two approaches is their practicality, which fits to the aim of the paper to provide guidance for effectively estimating the financial effects of mitigating CPV in supply chain management decisions, as discussed in the following sections.

\section{Total cost of ownership}

\subsection{Overview}

TCO is a methodology and philosophy which goes beyond the purchase price to include several other purchase-related costs (Bhutta and Huq, 2002). It is the term used to describe costs associated with the acquisition, use and maintenance of a good or service (Ellram and Siferd, 1993). TCO examines the cost associated with purchased goods and services throughout the entire supply chain, including the costs from the idea of the product/service (e.g. cost of working with a supplier to develop a new or improved part, in relationship with production and/or assembly systems) (Brad et al., 2018; Heilala et al., 2006), through warranty claims because of that part once the final product is used by the customer (Ellram, 1993).

According to the TCO approach, the buying firm needs to base sourcing decisions not just on adopting a "price only" focus, as found in the traditional approaches to supplier selection under supply chain risk conditions (Dupont et al., 2018; Yoon et al., 2018). Rather, firms need to determine which costs they consider most important or significant in the acquisition, possession, use and subsequent disposition of a good or service. Hence, in addition to the price paid for the item, a TCO approach may include other elements such as order placement, research and qualification of suppliers, transportation, receiving, inspection, rejection, replacement, downtime caused by failure and disposal costs, among many others (Ferrin and Plank, 2002).

The two primary conceptual insights provided by a TCO approach can be summarized as follows:

1 the evaluation of a broader spectrum of all the costs related to a 'TCO' perspective, considering acquisition costs, all the costs related to suppliers, and generally all internal costs; and

2 the evaluation of life cycle costs, which consider all the costs associated with using a given item from a given supplier during the entire life of the item, including costs incurred when the item is in use.

\subsection{Total cost of ownership for measuring commodity price risk mitigation}

Several models have been suggested for understanding TCO associated with purchasing a product or service. Ellram and Siferd (1993) suggest grouping purchasing activities into six categories: quality, management, delivery, service, communications and price. Another approach consists in looking at costs based upon the order in which the cost elements are incurred, following the transaction sequence: pre-transaction, transaction and post-transaction (LaLonde and Zinszer, 1976).

In TCO, the quoted price of the commodity is the starting point. Then, other factors considered important in the 
purchasing of a commodity are considered and replaced by a cost factor. Each issue is translated into a cost component that is added into a price adder formula (Bhutta and Huq, 2002). Finally, the total cost of each purchasing option is calculated: the best option is the one with the lowest total cost. Following the TCO approach, Table 1 reports some costs elements associated with the commodity purchase under different commodity price risk mitigation strategies, classified as pretransaction, transaction and post-transaction.

The analysis of the cost components related to the risk mitigation strategies - conducted through a TCO approach of commodity purchases - reveals many additional costs arise beyond the purchase price. These cost elements highlight the need to carefully revise the decision-making processes regarding risk mitigation strategies based on purchase price.

When organizations create their commodity purchasing strategy, there is a risk of paying limited attention to a detailed ex ante analysis of the consequences and benefits stemming after its implementation. A purchase price comparison is often the key criteria driving the purchasing strategy, although the practice may highlight additional expenses might occur, such as negotiating price adjustments, qualifying new suppliers and personnel travelling costs, for example. Furthermore, uncertainties and risks might increase, such as the risk of supply chain disruptions because of suppliers cancelling orders because they cannot offset price increases from their commodity purchases. For these reasons, the commodity purchasing strategy should holistically consider the costs related to the purchasing process, the risks generated by CPV and the total costs related to implementing commodity price risk mitigation strategies. Table 1 highlights examples of possible cost elements in a TCO model when selecting a commodity price risk mitigation strategy.

\section{Real options valuation}

\subsection{Overview}

ROV has been introduced in the literature as an approach that overcomes the limits of traditional methodologies for evaluating investment opportunities under uncertain environments. Traditional methods, such as those based on $\mathrm{DCF}$ - net present value, internal rate of return and discounted pay back period - implicitly assume investment benefits and, therefore, the "expected scenario" of cash flows are known and presume management's passive commitment to a certain operating strategy (Zhao et al., 2015; Wei and Tang, 2015; Boute et al., 2004). During project management and operations, especially in highly uncertain and dynamic environments, managers may make different choices about operating actions when new information from the market is available. The right, but not the obligation, to do something in the future represents a (real) option (Dixit and Pindyck, 1995). This concept emphasizes the manner in which investments create economic value through operating flexibility. Having a real option in a project means being able to react to unexpected market changes, assuring the capability to mitigate project risk, therefore improving project value (Chiara et al., 2007). This possible additional value needs to be considered during the decision-making process. A broad variety of real options have been studied in the literature including - for example - the option to defer production, temporarily shut down production, hold or abandon a project, decide the timing of investment, choose the production technology, inputs and outputs and to change a project's output mix (Amram and Kulatilaka, 1999; Trigeorgis, 1998; Majd and Pindyck, 1987; McDonald and Siegel, 1986).

Two key insights underlie the application of ROV. First, ROV builds upon the assumption that opportunity costs are associated with irreversible investments under uncertainty. This implies the possibility to defer committing resources under uncertainty is worthwhile (Trigeorgis, 1998). Second, ROV recognizes many investments create valuable follow-on investment opportunities (Amram and Kulatilaka, 1999). These insights suggest that certain up-front investments enable management to capitalize on favorable opportunities and mitigate negative events by proactively managing uncertainty over time in a flexible way (Kogut, 1991) rather than by attempting to avoid uncertainty. This managerial flexibility may be exploited, for example, when new information regarding market demand, competitive conditions or the viability of new processes technologies is available (Leiblein, 2003).

\subsection{Real options valuation for commodity price risk mitigation approaches}

Among different risk treatment strategies, risk transfer means passing the financial consequences of a risk to a third party (supplier, subcontractor, service, distributor, customer, etc.), whereas risk sharing means dividing it among different actors. Conversely, risk taking is a single-handed strategy that is characterized by the use of only internal risk management techniques (Lavastre et al., 2012; Hallikas et al., 2004; Harland et al., 2003). While risk transfer and risk sharing consist of passing some parts of risks and sharing it with others, risk taking is a decision made within the organization, thereby requiring the identification of appropriate and feasible approaches for its management.

The literature on SCRM has recognized the combination of redundancy and operational and strategic flexibility as effective practices for mitigating supply chain risk (Namdar et al., 2018; Daultani et al., 2015; Ho et al., 2015; Yu et al., 2015). Strategies that prioritize their mitigation capability on redundancy essentially maintain excess resources such as inventory and capacity. Among commodity price risk mitigation approaches, this is the case of forward buying and vertically integrating. Investments in creating supply chain flexibility can serve as an approach for mitigating the detrimental effects of commodity price volatility. We define flexibility in terms of the firm's ability to proactively react to environmental changes with little or negligible penalty and sacrifice in terms of time, operational efforts, cost or performance (Lu et al., 2017; Pérez et al., 2016; Upton, 1994). The choice of the mitigation strategies requires not only a deep understanding of all the costs associated with the strategies itself, beyond the purchase price, but also the assessment of the value created by the flexibility itself.

Firms can also create operational and strategic flexibility for mitigating CPV risk (Pellegrino et al., 2019). For instance, among flexible sourcing approaches, Switching Suppliers and Substituting Commodities are two flexibility-based commodity 


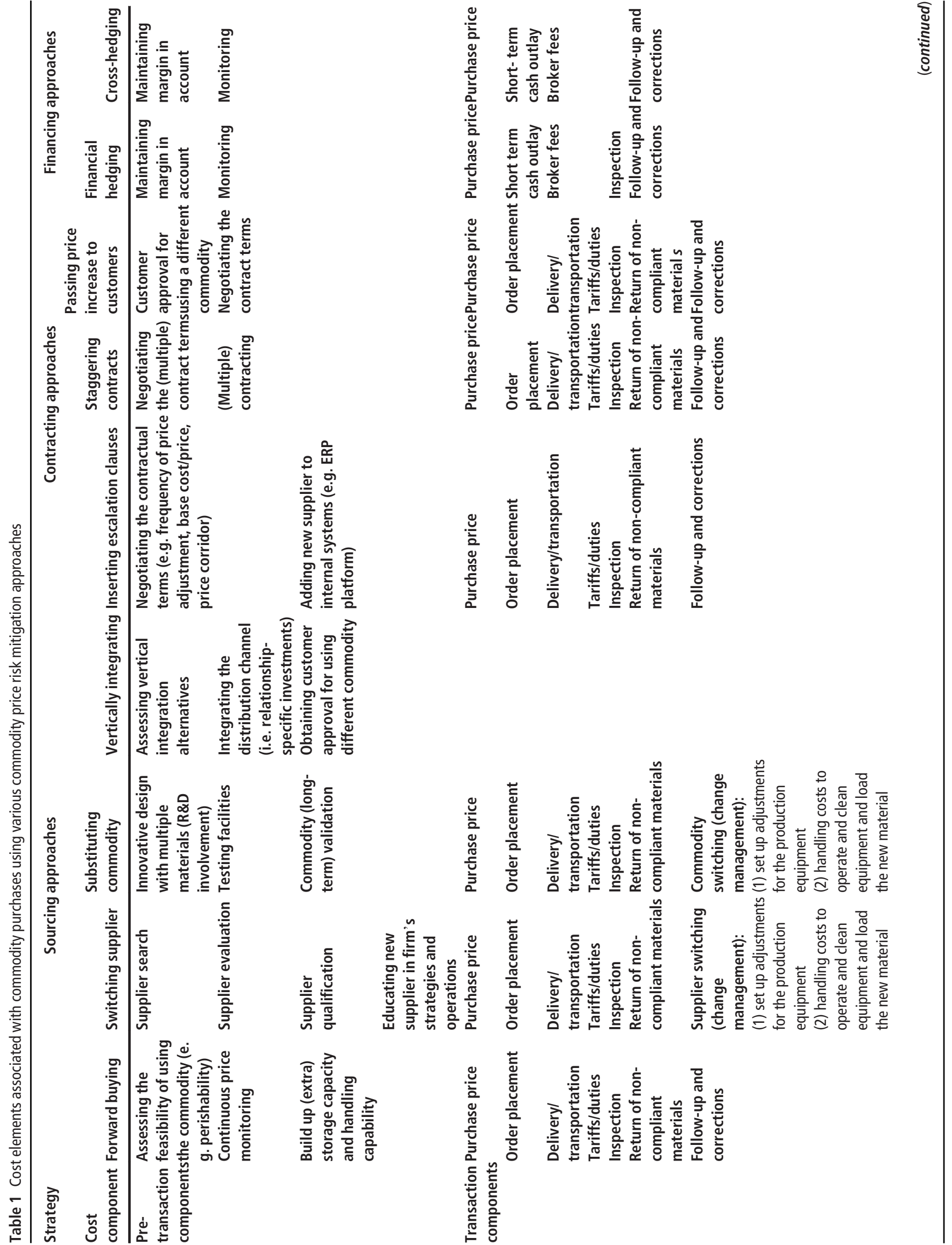




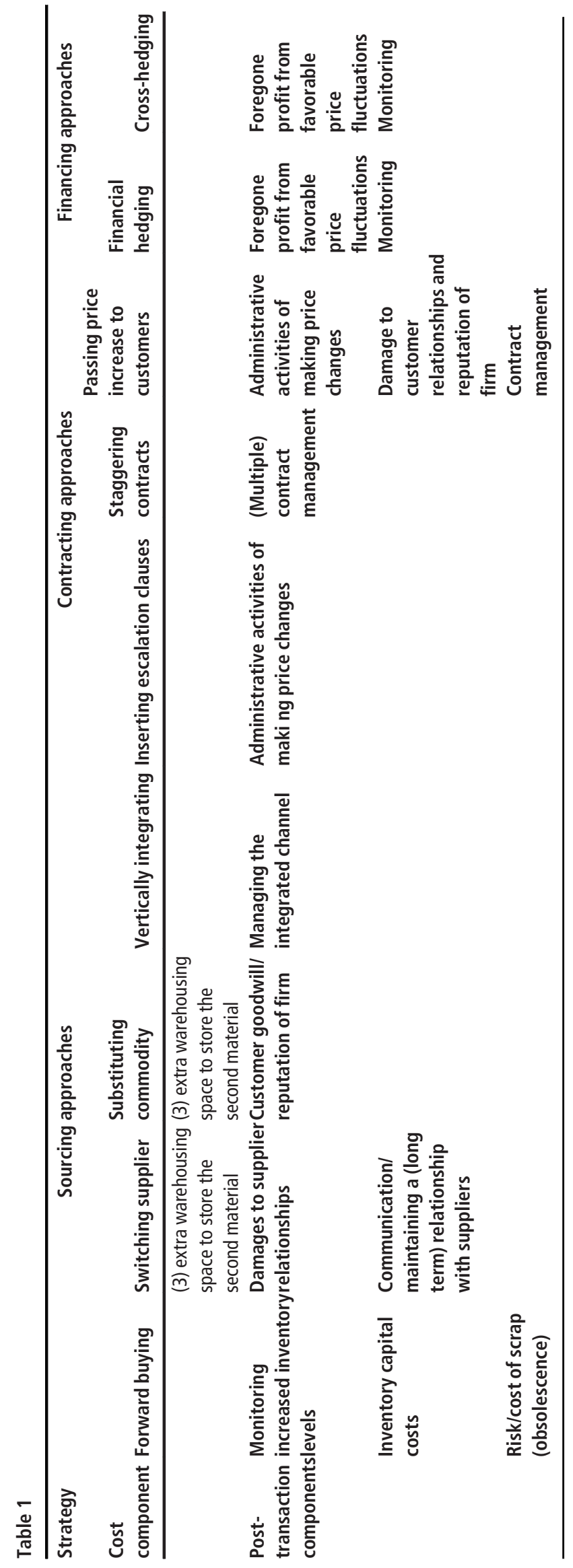


price risk mitigation approaches: the decision-maker will decide whether substituting commodities or switching suppliers is appropriate on the basis of the commodity prices and the cost of enabling such flexibilities. Inserting escalation clauses or financial hedging are examples of flexibility-based commodity price risk mitigation approaches among contracting and financial ones. Operationalizing and assessing these mitigation strategies requires modeling the managerial flexibility of the decisionmaker, considering both the price of commodities and the cost of flexibility itself. Any attempt to quantify this flexibility leads almost naturally to the concept of options. Hence, these approaches are analyzed in this paper by operationalizing them from an ROV perspective.

Although most of the commodity price risk mitigation approaches summarized in Table 1 provide firms flexibility in responding to commodity price changes, the four we will highlight with respect to ROV are switching suppliers and substituting commodities among the sourcing approaches, inserting escalation clauses among the contracting ones and financial hedging among the financial ones. Switching Suppliers provides a firm the ability, but not the obligation, to reconsider its cost structure in response to commodity price changes. The company will switch suppliers when the cost efficiency gains outweigh the aggregate transaction costs of setting up operational flexibility. Similarly, substituting commodities gives a firm an option to react to CPV by making the commodity substitution when there are favorable conditions, such as when the financial benefits gained through the substitution are greater than its costs. At the same time, however, to open an option, such as making a substitution technically and commercially viable, there is the need for upfront investments in $\mathrm{R} \& \mathrm{D}$, market research and material/supplier qualification, as well as the need for sustaining on-going supply chain costs to manage such flexibility. Inserting escalation clauses in contractual agreements with commodity suppliers allows the organization to define how often the commodity prices are reviewed and changed, the base "price" from which adjustments will be made, and if past or future prices will be changed. The company has the right, but not the obligation, to demand price adjustment when the actual prevailing price in spot market is above a base (predefined) target price. To have such a flexibility, administrative costs which depend on the frequency of review (monitoring) and price adjustment have to be sustained. Financial hedging gives companies needing to buy significant quantities of commodity the possibility to hedge against rising commodity price by taking up a position in the commodity futures market. In this way, the company secures a purchase price for a supply of commodity that it will require sometime in the future. If the commodity price increases, the company has the possibility to offset it by the gains in the futures market (i.e. the difference between the actual price of commodity and the price locked with the futures). To build this mitigation ability, the company has to pay the cost for entering into future contracts and monitoring the commodity spot price.

Figure 1 describes the discussed strategies from the perspective of ROV. It shows how an ROV model provides an approach for integrating and comparing seemingly incomparable issues (either qualitative or quantitative, either cost- or benefit-related), thus guiding the purchasing manager to select the commodity price risk mitigation strategy which ensures the required trade-off among such issues.

\section{Advantages and disadvantages of total cost of ownership and real options valuation}

TCO and ROV have their respective advantages and disadvantages with regard to measuring the financial effects from implementing commodity price risk mitigation strategies.

Figure 1 Flexibility-driven commodity price risk mitigation strategies from a real options valuation perspective

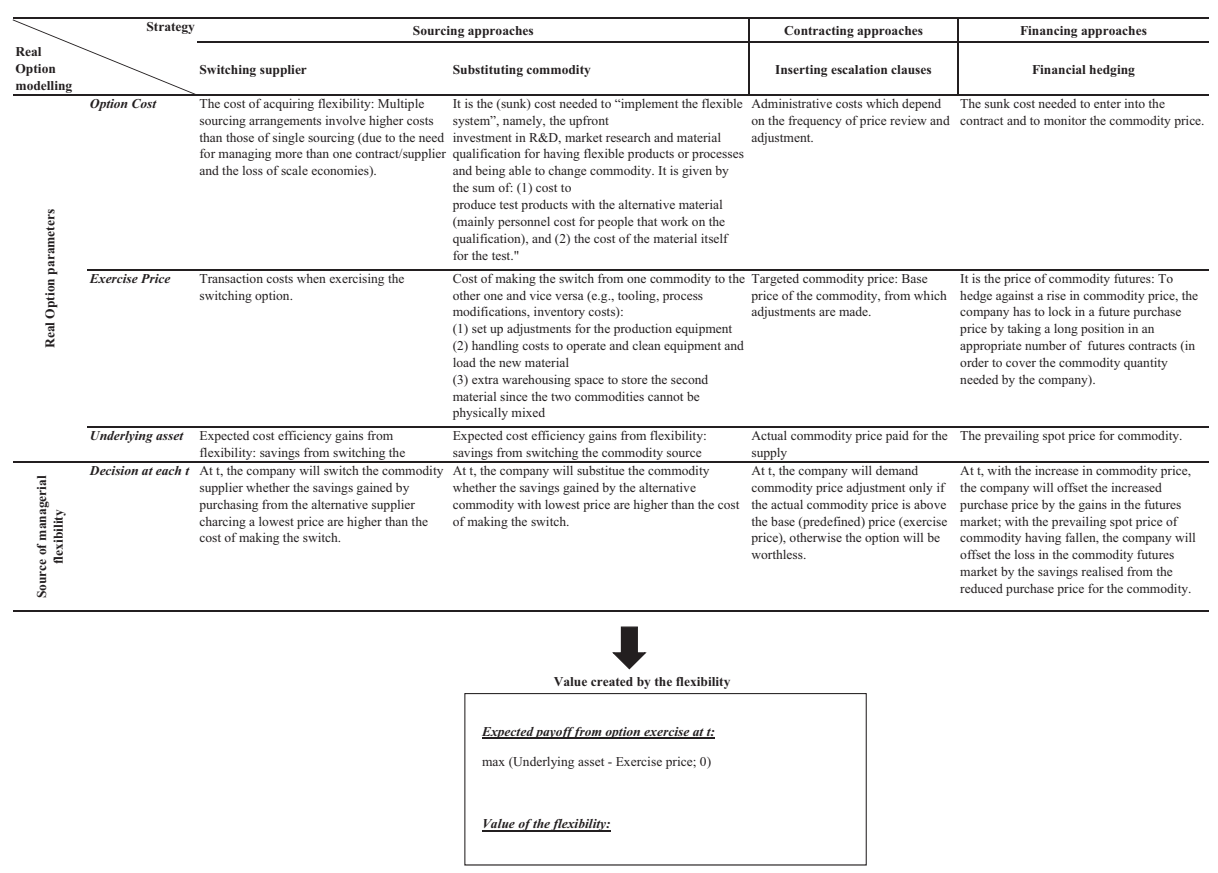


A summary of these advantages/disadvantages is proposed in Table 2 and is discussed below.

\subsection{Total cost of ownership advantages and disadvantages}

One advantage of the TCO approach concerns the potential thoroughness of incorporating many different cost elements associated with implementing a commodity price risk mitigation strategy. These can include, for example, investment (pre-transaction) costs in qualifying alternate supply sources, costs in creating flexibility in product design to facilitate substituting commodities, negotiating contracts with suppliers and/or customers for inserting escalation clauses and building inventory capacity in preparing for forward buys, among others. Further, additional cost elements (transaction costs) can likewise be incorporated, such as switching supply sources, changing production processes to use different commodities, adjusting payment amounts at specific time intervals from escalation clause agreements and transporting larger quantities from forward buys, for example. Other potential future (posttransaction) costs from implementing commodity price risk mitigation strategies can also be incorporated such as carrying additional inventory, losing customer confidence and goodwill from changing product materials, creating additional scrap and waste and experiencing unforeseen product failures and quality issues. These costs elements can be aggregated for better gauging the actual cost of implementing these strategies, beyond solely looking at the potential commodity price savings accruing from mitigating commodity price risk. However, some of these costs, especially post-transaction costs, can be very difficult to accurately assess.

Using TCO as a measurement approach provides supply management professionals, as well as other key organizational stakeholders, greater insight to supply chain processes, including those of their suppliers (Ellram, 1993). This information is critical for better preparing negotiations with suppliers (and even sometimes customers) in determining how best to address "what if" scenarios of significant commodity price movements, both in the short as well as long term. By understanding costs beyond those associated with the commodity prices themselves, such as its effects on supplier performance and internal costs, purchasing professionals can be better prepared to negotiate with suppliers, both for those with direct spend on commodities, as well as "value chain" purchases of suppliers acquiring commodities and the potential "cascading" effects of those commodity prices in the supply chain.

Although there are many reported benefits of TCO (Bhutta and Huq, 2002; Ellram, 1995), there are also various drawbacks associated with implementing this measurement approach for assessing commodity price risk mitigation strategies. The first consists of its complexity to implement and time it takes to collect the data and derive calculations, many of which are difficult to estimate and understand. Second, it is a static approach, where changes in the internal/external environment, such as changes in technology affecting cost structures and additional maintenance and operating costs, can influence the outcomes of the model. Being a deterministic model, TCO relies mostly on uncertain data, making it difficult to forecast the future expense or income for a specific purchase.

Another challenge with TCO models is potentially ignoring cost elements beyond mathematical measurement. For instance, in case of forward buying strategy, the model ignores the intrinsic value of the strategy that consists in eliminating the price volatility at an unknown cost, because there is no way to account for the risk of fixed prices being higher or lower than the fluctuating price. The essential TCO metric focuses only on cost, and because of this insight might select a mitigation strategy minimizing expenditures, rather than a strategy maximizing the return for the company. Finally, TCO ignores the benefits of flexibility in the supply chain because it is a static model.

\subsection{Real options valuation advantages and disadvantages}

The ROV as an analytic tool for measuring the effects of implementing a commodity price risk mitigation strategy has several benefits. First, an ROV model assesses the value created

Table 2 TCO and ROV advantages and disadvantages

\begin{tabular}{lll}
\hline Advantages & Disadvantages \\
\hline TCO & $\begin{array}{l}\text { Incorporates numerous cost elements associated with a given strategy into consideration } \\
\text { Considers costs beyond acquisition price (purchase price comparison) } \\
\text { Allows for the identification of costs that otherwise may remain hidden }\end{array}$ & $\begin{array}{l}\text { Complex and time consuming } \\
\text { Static system } \\
\text { Deterministic model relying mostly on } \\
\text { uncertain data }\end{array}$ \\
Provides a tool for negotiating with suppliers & $\begin{array}{l}\text { Great effort in tracking and maintaining } \\
\text { cost data } \\
\text { Often focuses on costs and not revenues } \\
\text { Often situation-specific } \\
\text { ROV }\end{array}$ & $\begin{array}{l}\text { Ignores flexibility benefits } \\
\text { Assesses the value created by the flexibility embedded in some strategies } \\
\text { Ability to model the decision-making process of the manager, even when quantitative and }\end{array}$ \\
qualitative factors need to be considered & Computational complexity \\
Focuses on cash flow and profit, not just cost minimization & Non-standardized calculation methods \\
Helps in comparing strategy performance (benchmark) against other approaches and self over & for option values \\
time & \\
Opportunity to understand the impact of changes in the environment &
\end{tabular}


from the flexibility embedded in a strategy by estimating the potential benefits of investing in specific approaches for mitigating commodity price risk given changing valuations. Further, these models provide managers insights to the decision-making process for adopting and implementing a given strategy, going beyond the cost elements themselves. Therefore, this approach can lead to a more holistic understanding of the strategy, considering both the costs (as TCO does), as well as its associated risks.

Another advantage of the ROV model is its analysis measuring the effectiveness of commodity risk mitigation strategies on maximizing cash flow and profit rather than minimizing cost. While a TCO model can provide significant insights on the cost of the approach, the ROV model will also analyze those costs, but as well provide estimates how the price of the commodity influences cash flow expenditures and profits from considering investments a priori. This analysis provides an opportunity to understand the impact of changes in both the internal and external environment on the effectiveness of the selected strategy.

However, the ROV also has several drawbacks associated with its use. Similar to TCO models, and maybe even more significant, there is computational complexity in deriving these models. This is because of the challenges of framing inputs to the model, as well as the mathematics involved. ROV requires using software programs such as Oracle Crystal Ball Decision Optimizer and Real Option SLS, which are often beyond the training of many purchasing professionals. An additional drawback is the lack of standardized models. There are different calculation methods for option values and their necessary assumptions and simplifications. The lack of standardization can yield significantly different results, depending on the calculation methods.

Although TCO and ROV have their respective advantages and disadvantages, they are complementary tools, which are able respectively - to fill the gaps and limitations of each other, contributing to a holistic management of cost, risk and mitigation strategies, as summarized in Table 3. The adoption of both the tools can provide insight to the effectiveness of implementing flexibility strategies for mitigating the detrimental financial effects of commodity price volatility. The next section provides a grounded example of how these approaches are applied.

\section{Measuring the cost of mitigating commodity price risk: a case example}

An aim of this paper is to provide insights through a case example to demonstrate the application of TCO and ROV and establish the benefits and challenges associated with their implementation. To provide a practical example, we selected a company listed in the Fortune ranking of the 100 best companies, which is one of the leaders in the fast-moving consumer goods industry. It is a multinational company offering a broad range of products across the world. The identity of this firm is concealed for confidentiality reasons. In this example, the company was exposed to commodity price volatility in the region including Europe, Middle East and Africa, where the company buys surfactants used in personal care and detergent, cosmetics, cleaning agents and detergents. In this example we considered realistic operational conditions and market values, adjusted by a specific coefficient for reason of confidentiality.

For mitigating commodity price risk, the company is interested in exploring the opportunity for substituting the commodity by using a natural surfactant - Commodity A (i.e. made with organic ingredients) or a synthetic one Commodity B (i.e. petroleum derived raw materials). The base case considers a total volume of $10 \mathrm{~K}$ tons of surfactants, a total investment of $\$ 0.1 \mathrm{~m}$ (option cost) to implement the flexible system for switching from one material to the other and a switching cost (exercise price) from natural surfactant to synthetic one and vice versa of $\$ 0.2 \mathrm{~m}$. After applying TCO and ROV approaches to the case, we revised the results with one of the managers involved in the case to get his perspective about the two approaches.

\subsection{Applying the total cost of ownership approach}

The analysis of the costs adopting the substituting commodity strategy according to the TCO approach has been carried out following Table 1. First, the possibility to switch the commodity depends on the ability of the final products/ materials to be obtained by using a different mix of commodities without changing its quality requirements. In other words, switching commodities is possible when a flexible formulation of the final product/material exists. To build such a flexible formulation, the R\&D department needs to search for the proper mix of commodities which produces commercially acceptable outputs. Hence, the company has to invest in the $\mathrm{R} \& \mathrm{D}$ activity to create a flexible formulation using different commodities. In this case, because such flexibility produces commercially acceptable outputs (with the same requirements), it is not required to obtain customer approval for using a different commodity. However, there are costs for testing alternative materials and validating the new commodity. The sum of all these (pre-transaction) cost elements to

Table 3 How total cost ownership and real options valuation contribute to effective purchasing decisions

Key elements of effective purchasing decisions Contribution of the tools

Holistic cost structure assessment (Purchasing price \& total cost consideration)

Assessment of risk dimensions

Cash flow, revenue and profit considerations

Support the decision-making process

Optimize flexibility

Aid in negotiating with suppliers

Measurement of commodity risk mitigation strategy effectiveness

\begin{tabular}{cc}
\multicolumn{2}{c}{ Contribution of the tools } \\
TCO & ROV \\
\hline $\mathrm{X}$ & $\mathrm{x}$ \\
$\mathrm{X}$ & $\mathrm{x}$ \\
$\mathrm{x}$ & $\mathrm{x}$ \\
& $\mathrm{x}$ \\
$\mathrm{x}$ & $\mathrm{x}$ \\
$\mathrm{x}$ & $\mathrm{x}$ \\
$\mathrm{x}$
\end{tabular}


implement the flexible system able to switch from one material to the other is the material qualification cost and accounts for $\$ 0.1 \mathrm{~m}$ (option cost).

Once the flexibility has been enabled in the system, the buyer will compare the purchase price of the alternative commodities $\mathrm{A}$ and $\mathrm{B}$, which have been estimated averaging the historical data of commodity prices paid by the company for the two sources. Contrary to what could be concluded with a rough assessment, the choice of the commodity to be used will not be based only on the lowest price, but will necessarily have to take into account if the lowest price commodity is not being currently used, the company will incur additional switching costs because of set up adjustments for the production equipment and handling costs to operate and clean the equipment, for example. In our specific case, these are the switching costs (exercise price) from a natural surfactant to a synthetic one and vice versa, which account for $\$ 0.2 \mathrm{~m}$.

The transportation cost also needs to be considered as an additional transaction cost. In this scenario, because the commodities are purchased from the same country and have similar physical characteristics, the transportation cost is the same and does not affect the price comparison. Finally, there are some post-transaction cost components associated to substituting commodity strategy, which are the loss of economies of scale incurred because very often contracts have a minimum volume, thus causing a loss of some discounts as company leverages a different commodity; higher scrap rate and market share loss because of different performance of the new commodity versus the other. Table 4 reports the main cost elements associated with the substituting commodity strategy.

Three main insights may be drawn from the TCO application for commodity price risk mitigation strategies. First, as shown in Table 4, the TCO approach provides a more holistic understanding of the costs associated with adopting the substituting commodity strategy, beyond the pure purchase price. In the specific case, this analysis is useful because it improves the buyer's understanding of the purchasing process and the related cost structure and therefore provides an excellent data source for negotiations. This is particularly valuable because it allows us to understand that an assessment based purely on the purchase price would be misleading for two reasons. On one hand, a choice based on the mere comparison of the average purchase price would lead to the conclusion that the substituting

Table 4 Simplified total cost ownership model for substituting commodity

Cost component

Pre-transaction components

Innovative design with multiple materials (R\&D involvement) $=55.000 \$$

Testing facilities $=30.000 \$$

Commodity (long-term) validation $=15.000 \$$

Transaction components

Purchase price of commodity $A=1.105,82 \$$ /unit (Tot. Volume 10.000 units)

Transportation cost (land freight) $=150 \$ /$ ton

Purchase price of commodity $B=1.384,40 \$ /$ unit (Total volume 10.000

units)

Transportation cost (land freight) $=150 \$ /$ ton

Commodity switching (change management):

Post-transaction components

Loss of economies of scale (if one contract has a minimum volume, you may lose some discounts as you leverage a different commodity)

Higher scrap rate (i.e. if the new commodity has different performance vs the other)

Market share loss (e.g. if the new commodity offers low performance vs the other)
Substituting commodity

\section{A.}

B

C

Total material qualitification cost $(A+B+C)=100.000 \$$

$D$ If company purchases commodity $A$ :

If company purchases commodity B:

$E$

(1) Set up adjustments for the production equipment

(2) Handling costs to operate and clean equipment and load the new material

(3) Extra warehousing space to store the second material Commodity switching (change management) $=200.000 \$$

$\mathrm{F}$

G

H

$\mathrm{TCO}=\mathrm{A}+\mathrm{B}+\mathrm{C}+\mathrm{D}+\mathrm{E}+\mathrm{F}+\mathrm{G}+\mathrm{H}$ 
commodity strategy is not appropriate because the commodity has a lower price (in this case Commodity A having a lower price than Commodity B). On the other hand, if instead we consider the real uncertainty of prices, we would choose the lowest-priced commodity from time to time, thus defining for the company a purchase cost given, time by time, by the lower price commodity (Figure 2). This would be a deceptive conclusion if we do not consider this choice having other costs. A more holistic evaluation of all cost components makes it possible to understand that switching costs arise beyond those under the direct purview of the purchasing department. The flexibility of the substituting commodity strategy involves business functions including, but going beyond, the purchasing department and therefore entails additional costs that must be considered. The perspective is that organizations need to align TCO as the KPI across all the functions involved in the sourcing process.

As a second insight, as other costs associated with the strategy are considered and assessed, the total cost of the strategy cannot be calculated by simply summing up all the cost elements associated with the strategy itself, as shown in the Table 4. Looking at each cost element, we can conclude they are not homogeneous. Specifically, the pre-transaction component represents a sunk cost (one-off cost for implementing the flexible system), while, contrarily, the transaction component is actually recurrent (this cost is charged anytime there is a commodity substitution). From additional discussions with this firm's management, more complex analyses require the need for the involvement of the finance function in determining how exactly these models should look like, which costs/benefits have to be included and how the cost elements should be calculated. This is a call to action for companies to involve the finance function to a greater extent in creating these models and validating measures and calculations.

Third, the TCO approach does not provide any information about the benefits created by using the substituting commodity strategy for the company. The TCO approach shows its limits in assessing the net value of flexibility-driven strategies, such as the commodity substitution strategy provided in this example. In this sense, TCO provides a full understanding of costs and benefits (in terms of saving opportunities) associated to the single purchasing option rather than a full assessment of the strategy as a commodity price risk mitigation approach.

The ROV model provides some solutions to these limitations. While TCO is still the primary approach at this firm, it requires a calculation of all costs involved. The challenge becomes that when there is uncertainty, such as including volatility commodity prices into the equation, the "risk" needs to be added as a cost in the TCO model. ROV is a way to quantify and embed those uncertainties into TCO.

\subsection{Application of real options valuation in the case study}

Using an ROV, we simulated the forecasted values of the two commodities prices (Commodity A and B) for a timeframe of 12 months based on the historical data of commodity prices paid by the company. In running this simulation, coherently with the literature (Pellegrino et al., 2019), we assume price to vary stochastically in time following a mean reverting process. In particular, the key parameters related to long run mean, annual volatility, mean reversion rate and the initial values are reported in Table 5. The outcome of the mathematical model in terms of total value of the flexibility, computed as the sum of expected payoffs over the strategy lifetime - option cost as described in Figure 1 - is shown in Figure 3. Because the model inputs are uncertain, specifically the price of the two commodities, and because the decision taken at each time $t$ is dependent on the evolution of such values along the strategy lifetime, the value created by the flexibility is not a determinist value, but rather a probability distribution. Looking at the statistics of the distribution, it is possible to observe that the value created by the flexibility ranges between a negative value equal to $-\$ 0.138 \mathrm{~m}$ up to a positive value equal to

Figure 2 Historical data on commodities prices: Commodity A, Commodity B and lowest price between A and B

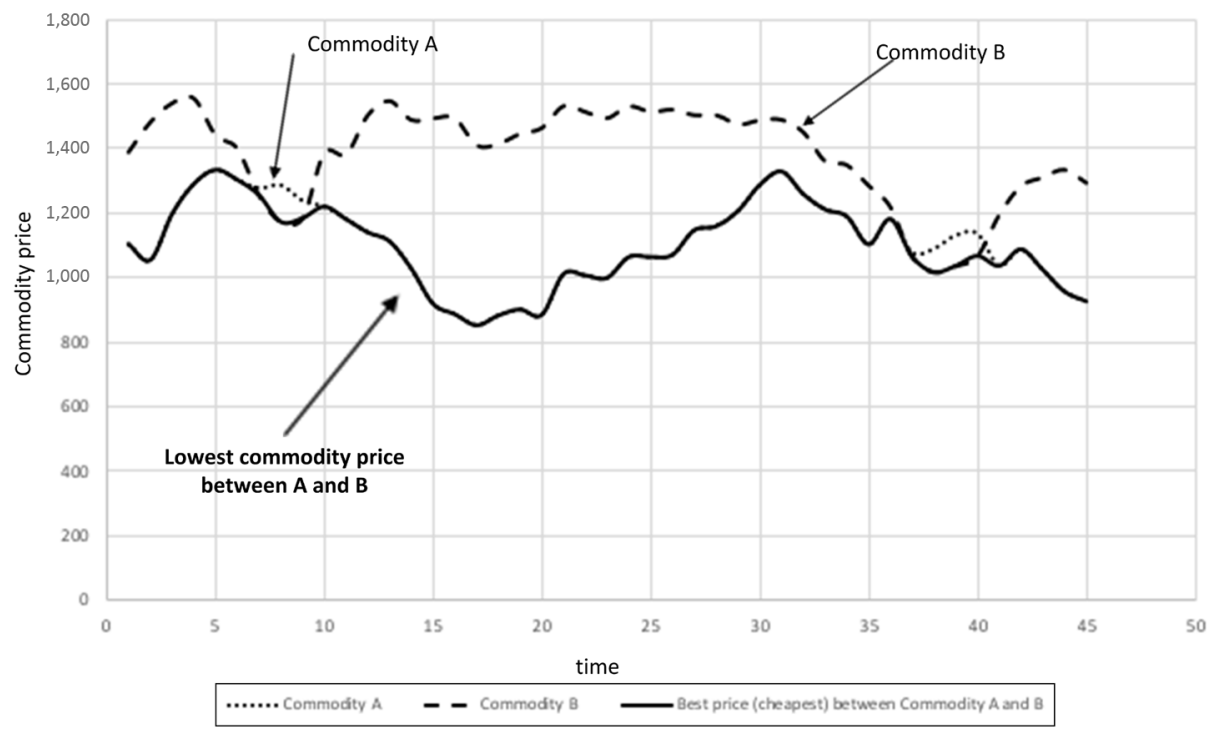


Table 5 Parameters of commodities prices

\begin{tabular}{lcccr}
\hline & Long run mean & Annual volatility & Mean reversion rate (in \%) & Initial value $\mathrm{S}_{0}$ \\
\hline Commodity A & $\$ 1,021.88$ & 0.0555 & 7.17 & $\$ 923.54$ \\
Commodity B & $\$ 1,171.58$ & 0.0513 & 3.06 & $\$ 1,094.21$ \\
\hline
\end{tabular}

Figure 3 Probability distribution of the value of flexibility

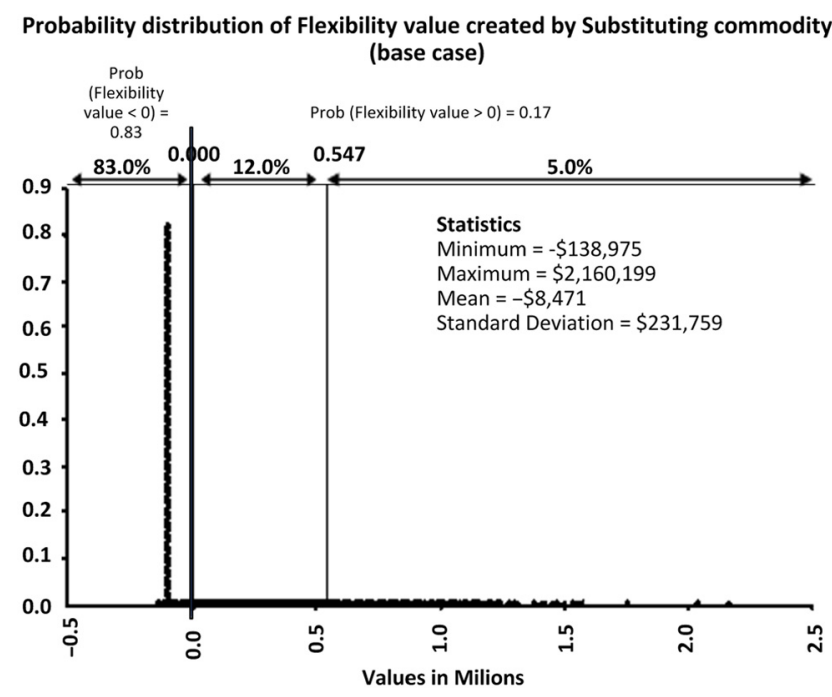

$\$ 2.160 \mathrm{~m}$. This means that against the initial price to develop the flexible system, the net benefits associated with the substituting commodity strategy are positive with a certain risk level (measured by the probability that the value of the flexibility is lower than 0). In particular, given the initial parameters considered as inputs of the model, we found that there is a chance of about $17 \%$ that this strategy positively impacts on the firm's profit delivering a value up to $\$ 2.160 \mathrm{~m}$. In the remaining $83 \%$ of cases, the strategy produces a loss for the firm up to $-\$ 0.138 \mathrm{~m}$.

We also carried out a sensitivity analysis on the switching cost (i.e. the exercise price of the option). The findings are depicted in Figure 4 which shows the probability distributions of the value of flexibility when switching costs change, whereas the statistics of the distributions are summarized in Table 6.
As the findings highlight, the mean value of the flexibility passes from being negative (a loss of $\$ 0.0085 \mathrm{~m}$ when Switching costs are $\$ 0.2 \mathrm{~m}$ ) to positive (a gain of $\$ 0.19 \mathrm{~m}$ when switching costs are $\$ 0.05 \mathrm{~m})$. This implies that the substituting commodity strategy becomes more effective in mitigating CPV (i.e. it delivers higher value), as expected, when the switching cost decreases. In other words, the impact of the strategy adoption on the firm's profit becomes more positive when the switching cost is lower. At the same time, the risk that the substituting commodity strategy results in a loss for the company, decreases from $83 \%$ to $43 \%$.

Three main insights may be drawn from the ROV application for commodity price risk mitigation strategies. First, it is interesting to observe the net benefit associated with these strategies (NPV of the flexibility) is positive with a certain risk level (measured by the probability that the value of flexibility is lower than 0). Beyond the specific numbers found for the value of flexibility in the discussed case, the findings show flexibilitydriven strategies may be effective in mitigating CPV because they positively contribute to the firm's cash flow and profits.

Second, the findings highlight that it is crucial for companies to carefully assess the value of these strategies before their implementation, because they are characterized by high implementation costs that need to be justified by the materialized cost savings. In fact, there is still a chance the value of the flexibility is less than 0 . It is essential to consider the value of the managerial flexibility to decide whether it is logical to pursue switch sourcing option when properly assessing their value. This shows the importance of adopting ROV to model such managerial flexibility and account for its value.

Finally, the sensitivity analysis of the value of flexibility to the variation of the switching costs shows how the value of such strategies is not just dependent on the CPV but also on the structural characteristics of such strategies and on the costs needed to develop flexibility. The effectiveness of the strategy in mitigating CPV increases when the switching cost decreases.

Figure 4 Results of sensitivity analysis: probability distribution of the value of flexibility when Switching costs change

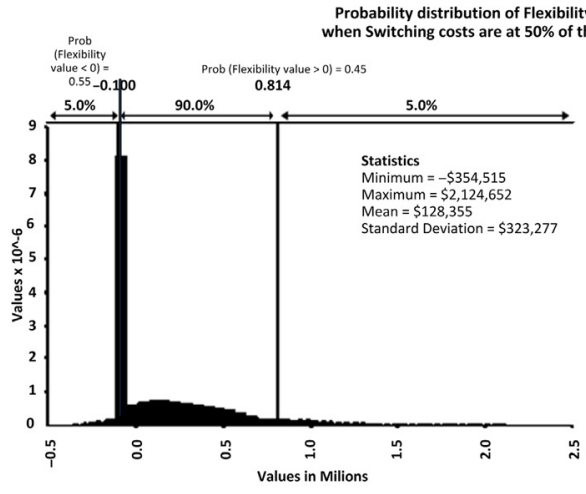

(a)

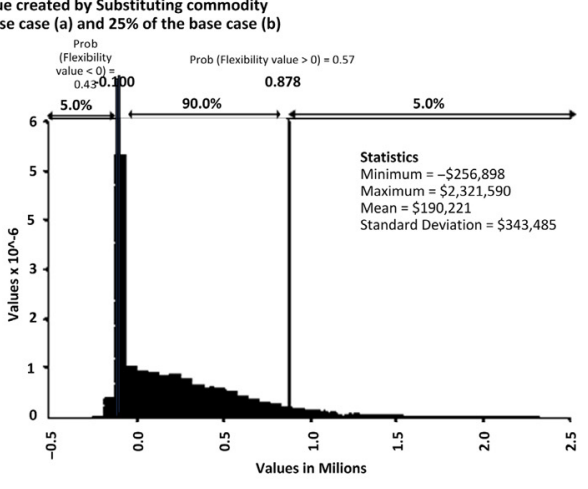

(b) 
Table 6 Results of sensitivity analysis: summary of statistics

\begin{tabular}{|c|c|c|c|}
\hline & Base case & Switching $-50 \%$ & Switching $-25 \%$ \\
\hline Investment MM\$ & 0.1 & 0.1 & 0.1 \\
\hline Switching MM\$ & 0.2 & 0.1 & 0.05 \\
\hline Volume kt & 10 & 10 & 10 \\
\hline Mean value of the flexibility: & $-\$ 0.0085 \mathrm{MM}$ & \$0.128MM & \$0.19MM \\
\hline Prob (Flexibility Value $>0$ ) & 0.17 & 0.45 & 0.57 \\
\hline \multirow[t]{2}{*}{ Range of flexibility value (Min-Max) } & $-0.138 \mathrm{MM} \$$ & $-0.354 \mathrm{MM} \$$ & $-0.256 \mathrm{MM} \$$ \\
\hline & $2.160 \mathrm{MM} \$$ & $2.124 \mathrm{MM} \$$ & $2.320 \mathrm{MM} \$$ \\
\hline
\end{tabular}

Reviewing the application of ROV to the case with management from the case company, the main insight we discovered was that there is not a general framework that can simplify these decisions: inputs need to be collected (hence, the importance of a cross-functional approach, with multiple inputs required from multiple functions) and a specific person or business function needs to own these calculations (which can be the finance function, purchasing, or another function determined by the firm).

\section{Implications and conclusions}

Creating a portfolio of flexible commodity price risk mitigation strategies may provide supply management professionals the capability to select the most effective option given CPV financial and operational risk exposure. This paper analyzes commodity price risk mitigation strategies under the perspective of their costs and performance by adopting two measurement approaches: the TCO and ROV. The case provides an example of the analysis by showing how such approaches can be used to address the effective and efficient selection of commodity price risk mitigation strategies. The findings and their discussion highlight how the two approaches do not seem to be alternative or mutually exclusive, but instead we discovered that ROV can serve as an extension of TCO because of its ability to calculate the net value of the strategy and its impact on the firm's bottom line. ROV considers not only costs associated with the strategy at various times in its life cycle and with different recurrence but also its benefits. Findings from this paper provides contributions to both the business and academic literatures. With regard to contributions to practice, we believe this study can provide supply chain professionals useful guidance for measuring the costs and benefits related to developing strategies for mitigating commodity price volatility. Supply chain flexibility is a key organizational and supply chain capability but requires investment. Holistically measuring the financial effects of flexibility investments is imperative for gaining executive management support in mitigating commodity price volatility. Using TCO and ROV for measuring the effectiveness of commodity price risk mitigation approaches ex ante is a step toward this direction. The application to the case and the discussion of findings show that TCO provides a focus on the costs associated with the commodity purchasing process, sets priorities regarding the areas in which it is needed to intervene to obtain benefits (i.e. saving opportunities) and provides excellent data for negotiations with suppliers. However, TCO does not provide a full assessment of the strategy itself and its mitigation capability. On the other side, ROV enables the aggregation of all the costs and benefits associated with the use of the strategy, including the value of flexibility as a mitigation capability, and synthesizes them into a single (economic) value which is the net value of the strategy. This helps in comparing strategy performance (benchmark) against other approaches and itself over time. Such characteristics makes ROV a powerful tool that can be used by purchasing managers not only to understand the effectiveness of the selected strategy in terms of its impact on firm's profit, but also to understand the impact of changes in both the internal and external environment on the effectiveness of the selected strategy (as the sensitivity analysis demonstrates). This will guide the manager in the selection of the appropriate strategy given actual conditions and future expectations.

The review of the case results with the company management also highlight interesting insights of what managers perceive about the two approaches:

- the importance of cross-functional collaboration for obtaining all the inputs needed for a proper application of TCO and ROV approaches;

- the need for scorecards to be aligned/synchronized across functions;

- the need for finance to have greater involvement;

- the ROV as a complement to TCO to embed risk into the equation;

- the need to understand who owns and leads the implementation of these capabilities in a company; and

- the need to run these analyses on a case-by-case basis because of the need to incorporate many factors, making it difficult to generalize the effectiveness of a certain strategy.

Finally, according to their management, the value of this approach is for sourcing organizations to be smarter on how to embed risk into calculations so that the correct resource allocations are made.

As for contributions to the academic community, this work begins to address an existing gap regarding the use of structured tools for analyzing the effectiveness of commodity price risk mitigation approaches. Prior research provides insight for comparing the benefits and drawbacks of TCO in the supply chain as a whole (Brad et al., 2018; Heilala et al., 2006) and in relation with other measurement approaches such as the analytic hierarchy process (Bhutta and Huq, 2002; Ramanathan, 2007) and data envelopment analysis (Garfamy, 2006; Ramanathan, 2007). TCO models have often been used 
for improving decisions associated with evaluating and selecting suppliers (Bhutta and Huq, 2002; Wouters et al., 2005), outsourcing (Ellram and Maltz, 1995), purchasing processes (Degraeve and Roodhooft, 1999) and more recently with specific services such as cloud computing (Han, 2011; Martens et al., 2012) and data centers (Koomey et al., 2007). We believe our paper extends current understanding of the benefits and drawbacks of TCO, and how other measurement approaches such as ROV can be used to complement the analysis of purchasing processes, especially those associated with creating flexibility in the supply chain.

Commodity price volatility directly affects the financial performance of organizations. Creating supply chain flexibility can be a strategic enabler for reducing the detrimental effects of significant commodity price shifts. Analyzing the effects on commodity prices alone, however, only provides a limited, and sometimes deceptive perspective on the "true cost" associated with mitigating this form of risk. TCO and ROV can provide firms a more holistic insight into how the use of flexible supply chain strategies can improve financial performance, and more specifically, which forms of supply chain flexibility may yield the greatest benefits.

The study has several limitations, which also offers potential directions for future research. One limitation is that the two approaches have been applied to only one specific case example. However, given the novelty of the methods adopted, the case example serves to highlight, beyond the specific numbers, interesting managerial insights from the use of the two approaches. Second, this study did not examine how TCO and ROV can be used in all of the CPV risk mitigation strategies presented in the literature, and instead only focused on the strategies used by the case study company (supplier switching and substitution). Future research may want to investigate how the effectiveness of other commodity price risk mitigation strategies are calculated using TCO and ROV. Such a study can draw out additional characteristics and cost and uncertainty elements for assessing the viability of other CPV mitigation approaches. Further, the application of the approaches to a higher number of and more complex cases may provide other useful insights. For instance, it could be used to understand if there are preferences about the use of the two approaches depending on the characteristics of context in which the firm operates, and the types of mitigation strategies adopted. In addition, the two methods can be applied in different industries to analyze whether and how different types of CPV, supply chain characteristics and risk mitigation strategies might lead to different results.

Commodity price volatility and risk have and will continue to present challenges to supply chain management professionals - as well as opportunities. Mitigating this form of risk through creating supply chain flexibility may provide financial benefits for firms in the long run. This paper provided insight as to how TCO and ROV can be implemented as decision analytic approaches for determining how organizations can make investments for better mitigating this form of risk in the supply chain and contribute to firm success.

\section{References}

Amram, M. and Kulatilaka, N. (1999), Real Options: managing Strategic Investment in an Uncertain World, Harvard Business School Press, Boston, MA.

Bandaly, D., Satir, A. and Shanker, L. (2014), "Integrated supply chain risk management via operational methods and financial instruments", International fournal of Production Research, Vol. 52 No. 7, pp. 2007-2025.

Bhutta, K.S. and Huq, F. (2002), "Supplier selection problem: a comparison of the total cost of ownership and analytic hierarchy process approaches", Supply Chain Management: An International fournal, Vol. 7 No. 3, pp. 126-135.

Boute, R., Demeulemeester, E. and Herroelen, W. (2004), "A real options approach to project management", International Fournal of Production Research, Vol. 42 No. 9, pp. 1715-1725.

Brad, S., Murar, M. and Brad, M. (2018), "Design of smart connected manufacturing resources to enable changeability, reconfigurability and total-cost-of-ownership models in the factory-of-the-future", International fournal of Production Research, Vol. 56 No. 6, pp. 2269-2291.

Caniato, F., Gelsomino, L.M., Perego, A. and Ronchi, S. (2016), "Does finance solve the supply chain financing problem? Supply chain management", Supply Chain Management: An International fournal, Vol. 21 No. 5, pp. 534-549.

Carmichael, D.G. (2015), "Incorporating resilience through adaptability and flexibility", Civil Engineering and Environmental Systems, Vol. 32 Nos 1/2, pp. 31-43.

Carmichael, D.G. (2016), "A cash flow view of real options", The Engineering Economist, Vol. 61 No. 4, pp. 265-288.

Chiara, N., Garvin, M.J. and Vecer, J. (2007), "Valuing simple multiple-exercise real options in infrastructure projects", fournal of Infrastructure Systems, Vol. 13 No. 2, pp. 97-104.

Costantino, N., Pellegrino, R. and Tauro, D. (2016), "Commodity price volatility mitigation in supply chain risk management: real options to assess the value of flexibilitydriven strategies", In: Proceedings of the Industrial Engineering and Engineering Management (IEEM), 2016 IEEE International Conference on. IEEE, pp. 129-133.

Daultani, Y., Kumar, S., Vaidya, O.S. and Tiwari, M.K. (2015), "A supply chain network equilibrium model for operational and opportunism risk mitigation", International fournal of Production Research, Vol. 53 No. 18, pp. 5685-5715.

Degraeve, Z. and Roodhooft, F. (1999), "Improving the efficiency of the purchasing process using total cost of ownership information: the case of heating electrodes at Cockerill Sambre SA", European fournal of Operational Research, Vol. 112 No. 1, pp. 42-53.

Dixit, A.K. and Pindyck, R.S. (1995), "The options approach to Capital investment", Harvard Business Review, Vol. 73 No. May/June, pp. 105-115.

Dupont, L., Bernard, C., Hamdi, F. and Masmoudi, F. (2018), "Supplier selection under risk of delivery failure: a decision-support model considering managers' risk sensitivity", International fournal of Production Research, Vol. 56 No. 3, pp. 1054-1069.

Ellram, L.M. (1993), "Total cost of ownership: elements and implementation”, International fournal of Purchasing and Materials Management, Vol. 29 No. 3, pp. 3-12. 
Ellram, L.M. (1995), "Total cost of ownership: an analysis approach for purchasing", International fournal of Physical Distribution E Logistics Management, Vol. 25 No. 8, pp. 4-23.

Ellram, L.M. and Maltz, A.B. (1995), "The use of total cost of ownership concepts to model the outsourcing decision", The International Fournal of Logistics Management, Vol. 6 No. 2, pp. 55-66.

Ellram, L.M. and Siferd, S.P. (1993), "Purchasing: the cornerstone of the total cost of ownership concept", fournal of Business Logistics, Vol. 14 No. 1, pp. 163-184.

Ferrin, B.G. and Plank, R.E. (2002), "Total cost of ownership models: an exploratory study", The fournal of Supply Chain Management, Vol. 38 No. 3, pp. 18-29.

Finley, B. and Pettit, J. (2011), "Creating value at the intersection of sourcing, hedging and trading", fournal of Applied Corporate Finance, Vol. 23 No. 4, pp. 83-89.

Fischl, M., Scherrer-Rathje, M. and Friedli, T. (2014), "Digging deeper into supply risk: a systematic literature review on price risks", Supply Chain Management: An International fournal, Vol. 19 Nos 5/6, pp. 480-503.

Garfamy, R. (2006), "A data envelopment analysis approach based on total cost of ownership for supplier selection", fournal of Enterprise Information Management, Vol. 19 No. 6, pp. 662-678.

Gaudenzi, B., Zsidisin, G.A., Hartley, J.L. and Kaufmann, L. (2018), "An exploration of factors influencing the choice of commodity price risk mitigation strategies", fournal of Purchasing and Supply Management, Vol. 24 No. 3, pp. 218-237.

Hallikas, J., Karvonen, I., Pulkkinen, U., Virolainen, V.-M. and Tuominen, M. (2004), "Risk management processes in supplier networks", International fournal of Production Economics, Vol. 90 No. 1, pp. 47-58.

Han, Y. (2011), "Cloud computing: case studies and total cost of ownership", Information Technology and Libraries, Vol. 30 No. 4, pp. 198-206.

Harland, C., Brenchley, R. and Walker, H. (2003), "Risk in supply networks", Fournal of Purchasing and Supply Management, Vol. 9 No. 2, pp. 51-62.

Heilala, J., Helin, K. and Montonen, J. (2006), “Total cost of ownership analysis for modular final assembly systems", International Fournal of Production Research, Vol. 44 Nos 18/ 19, pp. 3967-3988.

Ho, W., Zheng, T., Yildiz, H. and Talluri, S. (2015), "Supply chain risk management: a literature review", International fournal of Production Research, Vol. 53 No. 16, pp. 5031-5069.

Kaufmann, L., Wagner, C.M. and Carter, C.R. (2017), "Individual modes and patterns of rational and intuitive decision-making by purchasing managers", fournal of Purchasing and Supply Management, Vol. 23 No. 2, pp. 82-93.

Kogut, B. (1991), "Joint ventures and the option to expand and acquire", Management Science, Vol. 37 No. 1, pp. 19-33.

Koomey, J., Brill, K., Turner, P., Stanley, J. and Taylor, B. (2007), "A simple model for determining true total cost of ownership for data centers", Uptime Institute White Paper, Version, 2, available online: www.slideshare.net/datacenters/asimple-model-for-determining-true-total-cost-of-ownership

Kumar, R.L. and Park, S. (2019), "A portfolio approach to supply chain risk management”, Decision Sciences, Vol. 50 No. 2, pp. 210-244.
LaLonde, B.J. and Zinszer, P.H. (1976), "Customer service meaning and measurement", National Council of Physical Distribution Management, Chicago, IL.

Lavastre, O., Gunasekaran, A. and Spalanzani, A. (2012), "Supply chain risk management in French companies", Decision Support Systems, Vol. 52 No. 4, pp. 828-838.

Leiblein, M.J. (2003), "The choice of organizational governance form and performance: predictions from transaction cost, resource-based, and real options theories", Fournal of Management, Vol. 29 No. 6, pp. 937-961.

Liu, Z. and Wang, J. (2019), "Supply chain network equilibrium with strategic financial hedging using futures", European fournal of Operational Research, Vol. 272 No. 3, pp. 962-978.

Lu, D., Ding, Y., Asian, S. and Paul, S.K. (2017), "From supply chain integration to operational performance: the moderating effect of market uncertainty", Global Fournal of Flexible Systems Management, Vol. 19 NO. S1, pp. 163-168.

McDonald, R. and Siegel, D. (1986), "The value of waiting to invest", The Quarterly fournal of Economics, Vol. 101 No. 4, pp. 707-727.

Majd, S. and Pindyck, R.S. (1987), "Time to build, option value, and investment decisions", Fournal of Financial Economics, Vol. 18 No. 1, pp. 7-27.

Manikas, A. and Kroes, J. (2016), "Improved forward buying of commodity materials", International fournal of Production Research, Vol. 54 No. 15, pp. 4568-4583.

Martens, B., Walterbusch, M. and Teuteberg, F. (2012), "“Costing of cloud computing services: a total cost of ownership approach", Proceedings of the 45th HI International Conference on System Science (HICSS), pp. 1563-1572.

Matook, S., Lasch, R. and Tamaschke, R. (2009), "Supplier development with benchmarking as part of a comprehensive supplier risk management framework", International fournal of Operations \& Production Management, Vol. 29 No. 3, pp. 241-267.

Morssinkhof, S., Wouters, M. and Warlop, L. (2011), "Effects of providing total cost of ownership information on attribute weights in purchasing decisions", fournal of Purchasing and Supply Management, Vol. 17 No. 2, pp. 132-142.

Namdar, J., Li, X., Sawhney, R. and Pradhan, N. (2018), "Supply chain resilience for single and multiple sourcing in the presence of disruption risks", International fournal of Production Research, Vol. 56 No. 6, pp. 2339-2360.

Pellegrino, R., Costantino, N. and Tauro, D. (2019), "Supply chain finance: a supply chain-oriented perspective to mitigate commodity risk and pricing volatility", fournal of Purchasing and Supply Management, Vol. 25 No. 2, pp. 118-133.

Pérez-Pérez, M., Serrano Bedia, A.M. and López Fernández, M. C. (2016), "A review of manufacturing flexibility: systematising the concept", International fournal of Production Research, Vol. 54 No. 10, pp. 3133-3148.

Ramanathan, R. (2007), "Supplier selection problem: integrating DEA with the approaches of total cost of ownership and AHP", Supply Chain Management: An International fournal, Vol. 12 No. 4, pp. 258-261.

Sun, H., Chen, W., Ren, Z. and Liu, B. (2017), "Optimal policy in a hybrid manufacturing/remanufacturing system with financial hedging", International Fournal of Production Research, Vol. 55 No. 19, pp. 5728-5742. 
Trigeorgis, L. (1998), Real Options: Managerial Flexibility in Strategy and Resource Allocation, MIT Press. Cambridge, MA.

Upton, D.M. (1994), "The management of manufacturing flexibility", California Management Review, Vol. 36 No. 2, pp. 72-89.

Wakolbinger, T. and Cruz, J.M. (2011), "Supply chain disruption risk management through strategic information acquisition and sharing and risk-sharing contracts", International fournal of Production Research, Vol. 49 No. 13, pp. 4063-4084.

Wei, S. and Tang, O. (2015), "Real option approach to evaluate cores for remanufacturing in service markets", International Fournal of Production Research, Vol. 53 No. 8, pp. 2306-2320.

Wouters, M., Anderson, J.C. and Wynstra, F. (2005), "The adoption of total cost of ownership for sourcing decisions - a structural equations analysis", Accounting, Organizations and Society, Vol. 30 No. 2, pp. 167-191.

Yoon, J., Talluri, S., Yildiz, H. and Ho, W. (2018), "Models for supplier selection and risk mitigation: a holistic approach", International fournal of Production Research, Vol. 56 No. 10, pp. 3636-3661.

Yu, K., Cadeaux, J. and Luo, B.N. (2015), “Operational flexibility: review and Meta-analysis", International fournal of Production Economics, Vol. 169, pp. 190-202.

Zhao, F., Dash Wu, D., Liang, L. and Dolgui, A. (2015), "Cash flow risk in dual-channel supply chain", International fournal of Production Research, Vol. 53 No. 12, pp. 3678-3691.

Zsidisin, G.A. and Hartley, J.L. (2012), "Creating a commodity price risk management strategy", Supply Chain Management Review, Vol. 16 No. 2, pp. 46-53.

Zsidisin, G.A., Gaudenzi, B., Hartley, J.L. and Kaufmann, L. (2015), "Understanding commodity price volatility mitigation from transaction cost economics: preliminary results", In: Proceedings of the Paper Presented at the 24rd Annual IPSERA Conference. Amsterdam.

Zsidisin, G.A. Hartley, J.L. Kaufmann, L. and Gaudenzi, B. (2013), "Managing commodity price volatility and risk", CAPS Research. available online: https://knowledge.capsresearch.org/ publications/pdfs-protected/zsidisin2014priceOverview.pdf

\section{About the authors}

Barbara Gaudenzi, $\mathrm{PhD}$, is Associate Professor at the Department of Business Administration at the University of Verona, Italy. She is Director of the Master in Supply Chain Management (LogiMaster) and Risk Management (RiskMaster) at the University of Verona. Her research interests focus on supply chain management, B2B management and supply chain risk management. She has published in international journals such as International Fournal of Production Economics, Fournal of Purchasing and Supply Management, Industrial Marketing Management, International fournal of Logistics Management, Fournal of Logistics: Research and Applications, Corporate Reputation Review and others. Barbara Gaudenzi is the corresponding author and can be contacted at: barbara.gaudenzi@univr.it

George A. Zsidisin, PhD (Arizona State University), CPSM, is the John W. Barriger III Professor and Director of the Supply Chain Risk and Resilience Research (SCR3) Institute at the University of Missouri - St. Louis. Professor Zsidisin's research focuses on how firms assess and manage risk associated with supply disruptions and price volatility in their supply chains. He has published over 80 research and practitioner articles and seven books, including Supply Chain Risk: A Handbook on Assessment, Management and Performance; Managing Commodity Price Volatility: A Supply Chain Management Perspective; Handbook for Supply Chain Risk Management: Case Studies, Effective Practices, and Emerging Trends; and Revisiting Supply Chain Risk. His research on supply chain risk has been funded by the AT\&T Foundation and IBM, and he has received numerous awards, such as from the Institute for Supply Management, Deutsche Post, Council of Supply Chain Management Professionals, and the Decision Sciences Institute. Further, he is one of the founding members of the International Supply Chain Risk Management (ISCRiM) network, teaches and leads discussions on supply chain management and risk with various Executive Education Programs and numerous companies in the US and Europe, is co-Editor Emeritus of the fournal of Purchasing $\mathcal{E}$ Supply Management and serves on the Editorial Review Board for several academic supply chain journals.

Roberta Pellegrino, $\mathrm{PhD}$, is Assistant Professor of Management Engineering in the Department of Mechanics Mathematics and Management - Polytechnic University of Bari, Italy. Her main research interests are on public-private partnership/project financing, supply chain risk management, real options theory and other topics in the area of organizational process management (economic-management engineering). She obtained $\mathrm{PhD}$ in Advanced Production Systems from the Polytechnic University of Bari, in 2010. She is has authored and co-authored several publications in international journals and books and has presented more than 50 papers at national and international conferences. 